\title{
Septic Pulmonary Embolism in a Patient Who Was an Intravenous Drug Addict
}

\author{
Intravenöz Uyuşturucu Madde Bağımlısı Hastada Gelişen Septik Pulmoner Emboli
}

Fatih Tanrıverdi', Gülhan Kurtoğlu Çelik², Gül Pamukçu Günaydın², Selçuk Coşkun², Teoman Erşen²

'Department of Emergency Medicine, Necip Fazıl City Hospital, Kahramanmaraş, Turkey

2Department of Emergency Medicine, Atatürk Training and Research Hospital, Ankara, Turkey

\section{ABSTRACT}

Introduction: Septic pulmonary embolism (SPE) is a pulmonary infarction and infection that is caused by pulmonary embolization from an infected fibrin thrombus that occludes the pulmonary arteries. SPE is a rare subtype of pulmonary embolism clinically characterized by fever, respiratory distress, and pulmonary infiltrates seen on radiological imaging. In the chest computed tomography of SPE, multiple air cysts; wedge-shaped opacities in the periphery of the lungs; multiple diffuse, small opacities mimicking bronchopneumonia; bilateral nodules; and cavitary nodules in the lungs can be seen.

Case Report: A 34-week-old male patient presented to our emergency department with complaints of chest and back pain, shortness of breath, and coughing up bloody sputum. The patient was addicted to heroin for 10 years and was a smoker for 15 years. In his chest $x$-ray, multiple diffuse opacities were present in both lungs. Thoracic computed tomography revealed multiple hyperdense nodular lesions in both lung parenchyma. Since these findings were consistent with SPE, the patient was hospitalized in the intensive care unit for further treatment.

Conclusion: The initial clinical and radiological features are often not specific to the disorder, and therefore, it is difficult to make the diagnosis. In patients with predisposing factors, if symptoms and radiological findings are compatible with SPE, the diagnosis should be kept in mind. In this article, we present the case of a 34 -year-old male patient who was an intravenous drug addict and was diagnosed with SPE.

Keywords: Heroin addiction, intravenous drug abuse, pulmonary embolism

Received: 19.11.2013 Accepted: 13.01.2014

\section{ÖZET}

Giriș: Septik pulmoner emboli (SPE), septik flebitteki enfekte fibrin trombüsten akciğere embolizasyon sonucu pulmoner damarlarda tıkanıkık olmasına bağlı gelişen pulmoner enfarkt ve pulmoner enfeksiyon tablosudur. Pulmoner embolinin nadir görülen bir alt tipi olan SPE klinik olarak ateş, solunum sıkıntısı ile başvurur ve radyolojik görüntülemede akciğerlerde infiltrasyon görülür. SPE'nin toraks bilgisayarlı tomografisinde akciğer periferinde çoklu hava kistleri, çoklu, kü̈çük diffüz bronkopomoniyi taklit eden opasiteler, akciğer periferinde kama şeklinde opasiteler, akciğerde bilateral nodüller ve nodüllerde kavitasyonlar görülebilir.

Olgu Sunumu: Otuz dört yaşında erkek hasta bir haftadır olan göğüs ağrısı, sırt ağrısı, nefes darlığı, öksürük ve balgamla kan gelmesi şikayeti ile acil servisimize başvurdu. Hastanın 15 yıldır sigara kullanmakta ve 10 yıldır eroin bağımlısı olduğu öğrenildi. Çekilen akciğer grafisinde her iki akciğerde multiple diffüz opasiteler mevcuttu. Toraks tomografisinde her iki akciğer parankiminde solda daha belirgin olmaküzere multiple hiperdens nodüler lezyonlar görüldü. Bu bulgularla hasta SPE öntanısı ile yoğun bakıma yatııılarak tedavi edildi.

Sonuç: Semptomları uyumlu olan ve predispozan faktörleri olan hastalarda radyolojik bulgular da mevcutsa akla SPE getirilmelidir. SPE yönetiminde erken tanı, uygun antimikrobiyal tedavinin hemen başlanması, ekstrapulmoner enfeksiyon kaynağının da tedavisi önemlidir.

Anahtar Kelimeler: Eroin bağımlısı, intravenöz ilaç kötüye kullanımı, pulmoner emboli

Geliş Tarihi: 19.11.2013 Kabul Tarihi: 13.01.2014

\section{Giriş}

Septik pulmoner emboli (SPE), septik flebitteki enfekte fibrin trombüsten akciğere embolizasyon olması sonucu pulmoner damarlarda tıkanıkık, pulmoner enfarkt ve pulmoner enfeksiyon gelişmesine bağı bir klinik tablodur. Intravenöz kateter 
kullanımı, intravenöz uyuşturucu kullanımı ve immünsupresif tedavi kullanımındaki artış sebebi ile SPE sıklığı giderek artmaktadır (1). SPE'li hastalar acil servise ateş, dispne, öksürük, plöretik göğüs ağrısı ve hemoptizi ile başvurabilir. SPE nadir görüldüğünden ve belirti bulguları hastalığa özgü olmadığından acil serviste tanısı güç olabilir. Göğüs radyografisinde kavitasyon içeren bilateral dağınık periferal pulmoner opasiteler görülür (2). Bu opasiteler saatler günler içinde gelişebilir. İmmun yetmezlik, intravenöz uyuşturucu madde kullanımı, prostetik kalp kapağı, pacemaker enfeksiyonu, fokal ekstrapulmoner infeksiyon varlığı hastalığın gelişmesinde predispozan faktörlerdendir. En sık neden olan patojenler stafilokokal türlerdir (2). SPE tedavisinde sistemik antimikrobiyal ilaçlar kullanılır. Ancak sistemik antikoagülasyonun rolü tartışmalıdır. Özellikle intravenöz uyuşturucu kullanan hastalarda endokardit de tabloya eklenmiş olabilir $(1,2)$. Bu yazıda intravenöz uyuşturucu bağımlısı bir septik emboli olgusu sunuldu.

\section{Olgu Sunumu}

Otuzdört yaşında erkek hasta bir haftadır olan göğüs ağrısı, sırt ağrısı, nefes darlığı, öksürük ve balgamla kan gelmesi şikayeti ile acil servisimize başvurdu. Hastanın 15 yıldır sigara kullanmakta ve 10 yıldır eroin bağımlısı olduğu öğrenildi. Ek hastalık ya da düzenli kullandığı ilaç bulunmamaktaydı. Acil servise başvurusunda genel durumu orta, kan basıncı: 100/50 mmHg, nabız hızı: 110/dk, periferik oksijen saturasyonu: \%93, ateş: $38,5^{\circ} \mathrm{C}$ idi. Akciğer muayenesinde her iki akciğerde ronkus ve yer yer ralleri mevcuttu, her iki üst extremitede antekubital alanlarda çok sayıda enjektör iğnesi giriş yeri, kızarıklık ve ısı artışı mevcuttu. Hastanın yapılan bilateral alt extremite venöz doplerinde patolojik bulgu saptanmadı. Diğer sistemik muayeneleri normaldi. Laboratuvar tetkiklerinde WBC: 13.400/mL (normal: 4.00011.000), Hgb: 10.4 gr/dL (normal: 12-16), Htc: 31.2 (normal: 36-45), CRP: 98 mg/L (normal: 0-8), Eritrosit sedimentasyon hızı 54 mm/saat, kreatinin: $1 \mathrm{mg} / \mathrm{dL}$ (normal: 0,5-1,2), üre: 50 mg/dL (normal: 10-49), AST: 17 U/L (normal: 0-32), ALT: 34 U/L (0-33) olup kan elektrolitleri normaldi, ne yazık ki o dönemde D-Dimer ile ilgili hastanede problem olduğu için D-Dimer çalışılamadı. Çekilen akciğer grafisinde her iki akciğerde multiple diffüz opasiteler mevcuttu (Resim 1). Toraks tomografisinde her iki akciğer parankiminde solda daha belirgin olmak üzere multiple hiperdens nodüler lezyonlar görüldü (Resim 2). Lezyonların en büyüğü sol akciğer lingula inferior segmentinde yerleşim gösten plevral tabanlı 40x45 mm boyutunda santralinde kavitasyon görülen bir lezyondu. Ayrıca santralinde kavitasyon olmayan en büyüğü 15 mm olan multipl noduler dansiteler mevcuttu. Hasta bu bulgularla rapor da emboli net bir şekilde belirtilmemesine rağmen SPE öntanısı ile göğüs hastalıkları ve enfeksiyon hastalıkları bölümlerine danışılarak yoğun bakıma yatırıldı. Burada infektif endokarditten şüphelenilerek transtorasik ekokardiyografi yapıldı ve sonucu normal olarak değerlendirildi, kapaklarda vejetasyona rastlanmadı. SPE'de sıklıkla staphiloccus aureus etken olması sebebiyle hastaya intravenöz vankomisin ve ciprofloksasin tedavisi başlandı. Hastanın kan kültürlerinde üreme olmadı. Bir haftalık tedavi sonrası ateşi düşen, nazal kanülle 2 It'den oksijen alırken takipnesi olmayan, CRP ve sedimantasyon hızı

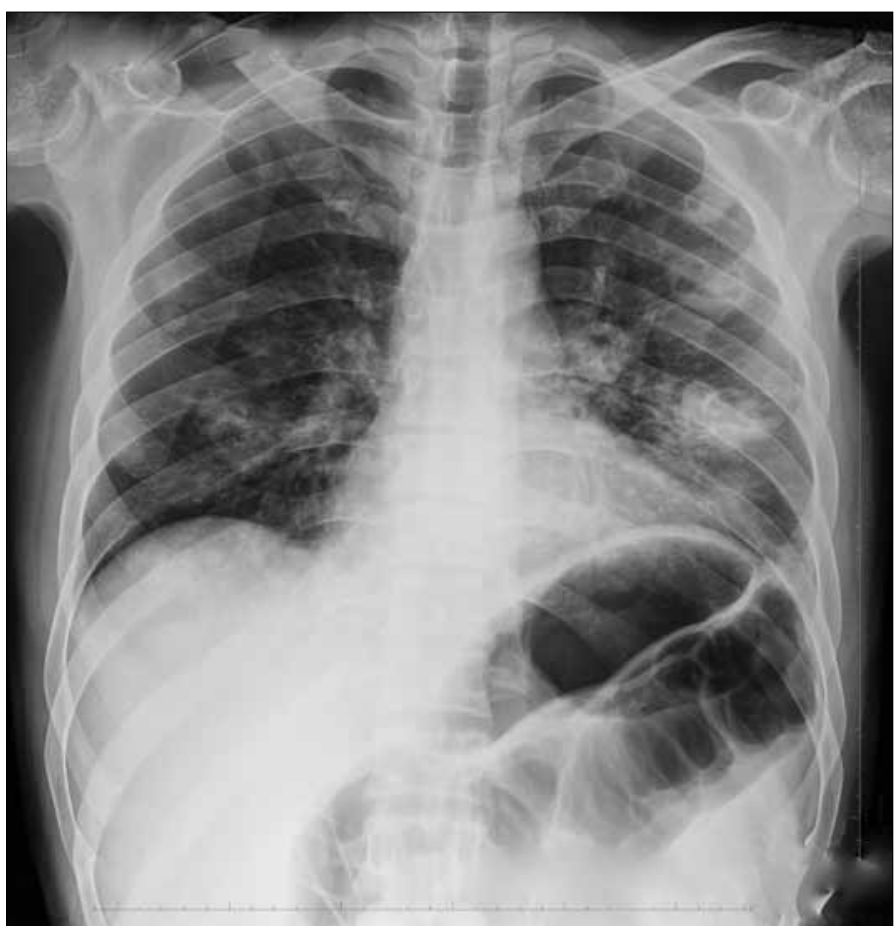

Resim 1. Her iki akciğerde multiple diffüz opasitelerin akciğer grafisinde görünümü

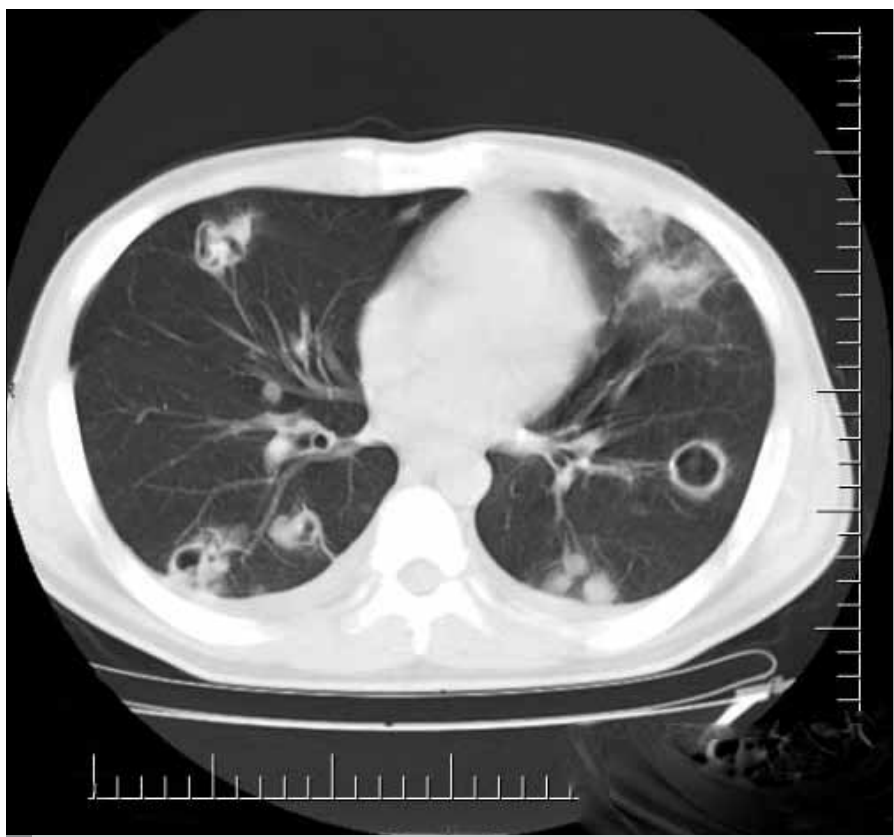

Resim 2. Her iki akciğer parankiminde multiple hiperdens nodüler lezyonların toraks tomografisinde görünümü

değerleri normale dönen, vital bulguları stabil olarak takip edilen, genel durumu düzelen hasta kendi isteği ile hastaneden ayrıldı.

\section{Tartışma}

Septik Pulmoner Emboli nadir görülen, semptom ve bulgularının spesifik olmaması sebebi ile tanısı zor olan bir hastalıktır. Önceki yıllarda septik embolinin en sık nedeni septik düşük ya da post 
puerperal uterin enfeksiyona bağlı septik pelvik tromboflebit ve baş boyun enfeksiyonları iken son yıllarda intravenöz kateterlerin yaygın kullanımı ve intravenöz ilaç ve uyuşturucu kullanımının artmasıyla SPE daha sık görülmektedir $(1,2)$. Illaç bağımlılığı, alkolizm, lenfoma, deri enfeksiyonları, konjenital kalp hastalıkları, osteomiyelit, mastoidit, hemodiyaliz uygulanan olgularda A-V şantlar, karaciğer apsesi, periodontal hastalıklar, toksik şok sendromu, Lemierre sendromu septik embolide altta yatan neden olabilir (3).

Septik Pulmoner Emboli'nin klinik semptomları ateş yüksekliği, dispne, öksürük, plöretik göğüs ağrısı ve hemoptizidir. Olgumuzda göğüs ağrısı, sırt ağrısı, nefes darlığı, hemoptizi mevcuttu. SPE'de bu semptomlara ek olarak ekstrapulmoner aktif enfeksiyon odağı saptanabilir (1). Bizim olgumuzda da antekubital alanlarda enfeksiyon tespit edildi.

Septik Pulmoner Emboli görüntülemesinde akciğerlerin düz grafisinde nodüler ve fokal infiltratlar, kama şekilli lezyonlar, kaviteler ve plevral lezyonlar görülebilir. Akciğerlerin en sık periferik, subplevral alanları etkilenir. Toraks tomografisinde ise akciğer periferinde çoklu hava kistleri, çoklu, küçük diffüz bronkopomoniyi taklit eden opasiteler, akciğer periferinde kama şeklinde opasiteler, iki taraflı nodüller ve nodüllerde kavitasyonlar görülebilir (4). Aseptik embolilerde de kavitasyon olabilir, fakat kavitasyon görüldüğünde tromboembolik infarkt üzerine bakteriyel enfeksiyon eklenmiş olabileceği düşünülmelidir (5). Olgumuzda her iki akciğer parankiminde santralinde kavitasyon görülen multiple hiperdens nodüler lezyonlar ve santralinde kavitasyon olmayan multipl noduler dansiteler mevcuttu.

Septik Pulmoner Emboli etyolojisinde sıklıkla staphylococcus aureus etkendir (2). Stafilokokların yanısıra viridan streptokoklar ve klebsiella pnomonia da sebep olabilir (6). Olgumuzda alınan kan kültürlerinde üreme olmamış, ampirik olarak başlanılan vankomisin ve ciprofloksasin tedavisine yanıt alınmıştır.

Septik Pulmoner Embolili olgularda triküspit kapakta vejetasyonlar, kapak yetmezliği ve paravalvular apseler görülebilir, bu sebeple bu hastalara ekokardiyorafi yapılması gereklidir. Transözefageal ekokardiyografi, küçük vejetasyonların görüntülenmesinde transtorasik ekokardiyografiye göre daha üstün bir tetkiktir (2). Olgumuzda transözefageal ekokardiyografi hastanede yapılamadığından transtorasik ekokardiyografi yapılmış ve vejetasyon görülmemiştir. Bunun sebebi vejetasyon olmaması ya da transtorasik ekokardiyografide görüntülenememiş olması olabilir.

Septik Pulmoner Emboli ayırıcı tanısında tüberküloz, mantar ve gram (-) enfeksiyonlar, paraziter enfeksiyonlar (kist hidatik), metastatik lezyonlar, romatoid artrit, Wegener granulomatozisi düşünülmelidir. Bu olguda semptom ve bulguların uyumlu olması, hastada predispozan faktör olarak intravenöz uyuşturucu kullanımı hikayesi olması, toraks tomografisinde SPE ile uyumlu bulguların görülmesi ve kaynak tromboflebit odağının tespit edilmiş olması nedeniyle septik pulmoner emboli düşünüldü.

\section{Sonuç}

Septik Pulmoner Emboli tanısı için belirlenmiş kesin kriterler olmadığından acil serviste tanısını koymak zor olabilir. SPE yönetiminde erken tanı, uygun antimikrobiyal tedavinin hemen başlanması, ekstrapulmoner enfeksiyon kaynağının da tedavisi önemlidir. Acil serviste sık görülmeyen bu hastalık akla getirilmezse tanısı kolaylıkla atlanabilir. Acil serviste SPE tanısını koyarken predispozan risk faktörlerinin olması, ateş, radyolojik olarak multiple periferal subplevral hava kistleri veya nodüllerin olması yardımcıdır. Erken tanı ve uygun antimikrobiyal tedavi ile potansiyel komplikasyonların gelişmesi engellenebilir ve tam iyileşme görülebilir. Bu sebeple predispozan faktörlerin olduğu hastalarda SPE tanısı akla getirilerek toraks tomografisi çekilmelidir.

Informed Consent: Informed consent was not received by the patient.

Peer-review: Externally peer-reviewed.

Author Contributions: Concept - F.T.; Design - G.K.Ç.; Literature Review - G.P.G., T.E.; Writer - G.K.Ç., G.P.G.; Critical Review - S.C.

Conflict of Interest: No conflict of interest was declared by the authors.

Financial Disclosure: The authors declared that this study has received no financial support.

Hasta Onamı: Hasta kimlik bilgileri gizli tutulduğundan ve herhangi bir girişim yapılmadığından hasta onamı alınmadı.

\section{Hakem Değerlendirmesi: Dış bağımsız.}

Yazar Katkıları: Fikir - F.T.; Tasarım - G.K.Ç.; Literatür taraması - G.P.G., T.E.; Yazıyı yazan - G.K.Ç., G.P.G.; Eleştirel İnceleme - S.C.

Çıkar Çatışması: Yazarlar herhangi bir çıkar çatışması bildirmemişlerdir.

Finansal Destek: Yazarlar bu çalışma için finansal destek almadıklarını beyan etmişlerdir.

\section{Kaynaklar}

1. Morris TA, Fedullo PF. Pulmonary Thromboembolism. In Mason RJ, Murray JF, Nadel JA. Editors. Textbook of Respiratory Medicine. 5th ed. Saunders; 2010. p.1216

2. Cook RJ, Ashton RW, Aughenbaugh GL, Ryu JH. Septic pulmonary embolism: presenting features and clinical course of 14 patients. Chest 2005; 128: 162-6. [CrossRef]

3. Doğan C, Şener S, Kıral N, Torun E, Salepçi B, Çağlayan B. Diş Çekimine Ikincil Gelişen Septik Pulmoner Emboli. J Kartal TR 2011; 22: 79-83.

4. Jaffe RB, Koschmann EB. Septic pulmanry emboli. Radiology 1970; 96:527-32. [CrossRef]

5. Jorens PG, Van Marck E, Snoeckx A, Parizel PM, Nonthrom-botic polmonary embl-olizm. Eur Respir J 2009; 34: 452-74. [CrossRef]

6. Lee SJ, Cha SI, Kim CH, Park JY, Jung TH, Jeon KN, Kim GW. Septic pulmonary embolism in Korea: Microbiology, clinicoradiologic features, and treatment outcome. J Infect 2007; 54: 230-4. [CrossRef] 